be to ensure that no one is deprived of medical attention because of lack of means to pay for it. It agrees with John Stuart Mill that a Government " cannot have too much of the kind of activity which does not impede but aids and stimulates individual execution and development." However, when it came to deciding how to apply this dictum to the Health Service the Scottish Committee could not agree.

\section{Dietary Treatment of Phenylketonuria}

Does the early dietary treatment of phenylketonuria ${ }^{1}$ prevent intellectual deterioration ? The answer to this question could be given by a controlled trial, but it is doubtful whether this would now be acceptable, so evidence on the effect of a diet low in phenylalanine must be obtained in other ways.

A simple comparison between the intelligence quotients of treated and untreated patients would not be valid unless both groups were similar in a number of factors-namely, age at diagnosis and at testing, level of serum phenylalanine at the same age, social experience and intelligence level of parents, and number of normal sibs. It is unlikely that two such groups could now be found. To take the mean I.Q. of untreated cases in institutions would be valueless because of the likelihood of intellectual deterioration with prolonged institutional care, and in any case such patients constitute a group selected from the population because of their low intelligence and not because of their phenylketonuria.

Recently investigators in Great Britain and the U.S.A. ${ }^{2}$ have combined, using common methods of testing, to discover whether there is a statistically significant correlation between early treatment and the level of intelligence. They studied 112 children, all having at least one unaffected member of the family who could be tested. Their cases were divided into eight groups according to the age at which dietary treatment was started, the youngest age group being from birth till one month of age and the oldest 48-72 months. They found that the longer the delay in treatment the lower was the I.Q. Nevertheless, the intelligence of those treated within the first month of life and tested at the age of 5 years was lower on average for their age than that of their parents or unaffected sibs. The authors concluded that " intellectual damage from phenylketonuria can apparently be ameliorated by adherence to a diet low in phenylalanine, and that treatment should begin as soon as possible following birth." They emphasized that even under ideal conditions of treatment no guarantee of a normal intelligence could be given.

In a study from Toronto $^{3}$ these findings were confirmed, and the important observation was made that the performance at school of even those children whose treatment was started within the first month of life and had a normal I.Q. was much worse than would have been expected for their intelligence score. One-fifth of the treated children showed autistic behaviour patterns. It was found, as has been observed before, that there was a group of children with low (less than

Clayton, B., Moncrieff, A., and Roberts, G. E., Brit. med. f., 1967, 3, 133.

2 Dobson, J., et al., New Engl. f. Med., 1968, 278, 1142. Hackney, I. M., Hanley, W. B., Davidson, W., and Lindsao, L., 7.
Pediat., 1968, 72, 646.
$25 \mathrm{mg}$. per $100 \mathrm{ml}$.) diagnostic levels of serum phenylalanine; in these children autistic behaviour was relatively common. In no instance was there a genuine increase in intelligence score during treatment, and four children actually deteriorated while on treatment. Nevertheless, it was concluded that if treatment is started during the first two months after birth the I.Q. is likely to be above $70 \%$.

Though the case for dietary treatment of phenylketonuria appears conclusive within the limits of the available evidence, more work is needed to sort out the various types of enzyme disorder which cause a raised level of serum phenylalanine. It is possible that dietary treatment may be actually harmful in some instances. Moreover, there is the possibility that prolonged overtreatment, with abnormally low levels of serum phenylalanine, may prevent normal intellectual development. Not only have I. M. Hackney and his colleagues at Toronto drawn attention to the inadequacies of simple psychometric methods in the assessment of children with phenylketonuria, they also suggest that permanent intellectual incapacity may result from the prolonged and intense family anxiety surrounding the rigid adherence to the diet.

\section{Suppressing Rh-immunization}

In European populations the commonest cause of haemolytic disease of the newborn is the formation of antibodies by the mother against foetal red cells possessing the $R h_{o}$ (or $D$ ) antigen component of the rhesus blood group system. The $\mathrm{Rh}$-negative women form antibodies against the rhesuspositive foetal red cells. In routine laboratory practice rhesus grouping of blood is actually $\mathrm{D}\left(\mathrm{Rh}_{\mathrm{o}}\right)$ grouping, though other antigens can occasionally cause trouble.

The most important cause of Rh-immunization of the mother in pregnancy is transplacental bleeding occurring at about the time of delivery. ${ }^{12}$ Foetal red cells can be detected in maternal blood, and the number found can be expressed as a " foetal cell score." Under appropriate conditions foetal red cells gaining entry to the maternal circulation provide the antigenic stimulus for the formation in the mother of $\mathrm{Rh}$ antibodies. These can then cross the placenta into the foetal circulation and cause haemolytic disease in the foetus. If the red cells of the foetus and mother are also ABO-incompatible, then formation of $\mathrm{Rh}$ antibody is much less likely to occur. This observation, which was made so long ago as $1943,{ }^{3}$ suggested by analogy that it might be possible to prevent Rhimmunization in ABO-compatible pregnancies by passive administration of anti-Rh antibody. ${ }^{14}$ This method of prophylaxis has been supported by experimental observations, ${ }^{15}$ and clinical trials have now shown convincingly that the injection of $1 \mathrm{ml}$. of anti-D (anti- $\mathrm{Rh}_{\mathrm{o}}$ ) gammaglobulin containing $200 \mu \mathrm{g}$. anti-D into Rh-negative mothers who have given birth to a first $\mathrm{Rh}$-positive, ABO-compatible infant is effective in suppressing primary immunization if given within 48-72 hours of delivery. ${ }^{267}$ So far relatively few failures have been reported. ${ }^{2}$ The precise mechanism of protection is obscure. It is unlikely that it is simply due to accelerated removal of foetal cells from the maternal circulation, and it has been suggested that the anti-D gammaglobulin binds to antigen sites on fragments of red cells after they emerge from macrophages, thus preventing their attachment to receptors on antibody-forming cells. ${ }^{8-10}$ 
The paper by Dr. J. C. Woodrow and W. T. A. Donohoe which appears in the B.M.f. this week at page 139 is a further contribution to the natural history and prevention of $\mathrm{Rh}$ immunization in pregnancy. Their work emphasizes that primary immunization occurs as a result of the first pregnancy (though no antibody can be detected) and that a very few foetal cells passing over during the next Rh-positive, $\mathrm{ABO}$-compatible pregnancy will lead to the rapid appearance of anti-Rh antibodies. They also provide more evidence that immunization, both primary and secondary, may follow from the entry of less than $0.1 \mathrm{ml}$. foetal blood into the maternal circulation, representing a foetal cell score of $0-4$. This was more often the case at the end of the second Rh-positive, ABO-compatible pregnancy than after the first.

Anti-D gammaglobulin is now in routine use in the United Kingdom for preventing $\mathrm{Rh}$-immunization, but because supplies are limited its use has been restricted to $\mathrm{Rh}$-negative primiparae who give birth to an $\mathrm{Rh}$-positive, ABO-compatible infant and in whom the foetal red cell score is 5 or more, this representing $0.2 \mathrm{ml}$. or more of foetal blood. But recently the Ministry of Health has recommended that treatment should now be based on finding any foetal cells. The report of Woodrow and Donohoe shows that the former criterion of selection leaves unprotected two-thirds of the cases in which anti-Rh antibodies might be expected to develop after the next Rh-positive, $\mathrm{ABO}$-compatible pregnancy, these cases having foetal cell scores of $0-4$. It seems, therefore, that the foetal cell score shortly after delivery is not a reliable way of selecting all patients for treatment, since a significant number of women who subsequently become immunized have no detectable foetal cells. Furthermore, the method of detecting and counting foetal cells can present difficulties in inexperienced hands, yet many hospital laboratories are now burdened with the additional task of providing this service. It is becoming apparent that to protect the maximum number of patients at risk the best policy would be to give anti-D to all $\mathrm{Rh}$-negative women who give birth to an Rh-positive, $\mathrm{ABO}$-compatible infant and in whom antibodies have not been detected, regardless of parity or foetal cell score. Even patients with $\mathrm{ABO}$-incompatible infants have some, though a much smaller, risk of becoming immunized, and a case exists for treating them as well. It is probably also wise to treat all previously unimmunized Rh-negative women who abort, since it is usually not possible to ascertain the blood group of the abortus. The practicability of such a policy will obviously depend on the supply of anti-D gammaglobulin of suitable potency, and until there is enough some degree of selection of cases for treatment is necessary. It is hoped that enough anti-D will shortly be available to meet the needs of all $\mathrm{Rh}$-negative primiparae at risk.

Finally, there is the problem of what constitutes an effective dose of anti-D gammaglobulin, and on this question the Medical Research Council is at present conducting a trial. The 200- $\mu$ g. dose now in use will clearly prevent immunization in the great majority of cases, since most transplacental haemorrhages are small. But occasionally a large haemor-

Finn, R., et al., Brit. med. f., 1961, 1, 1486.

2 Clarke, C. A., Lancet, 1968, 2 , 1 .

Levine, P., ₹. Hered., 1943, 34, 71

- Finn, R., Lancet, 1960, 1, 526.

Stern, K., Goodman, H. S., and Berger, M., F. Immunol., 1961, 87, 189.

Combined Study, Brit. med. F., 1966, 2, 907.

Freda, V. J., et al., Ұ. Amer. med. Ass., 1967, 199, 390.

Mollison, P. L., Brit. F. Haemat., 1968, 14, 1 .

Sisskind, G. W., Transfusion, 1968, 8, 127.

Pollack, W., Gorman, J. G., Hager, H. J., Freda, V. J., and Tripodi, D., Transfusion, $1968,8,134$. rhage (up to $150 \mathrm{ml}$.) occurs, and in such cases the usual dose may be ineffective. It would be wasteful to give all women at risk a larger dose of anti-D in order to cover this very small group of cases. These large haemorrhages will cause high foetal red cell scores, and to detect such cases (constituting perhaps less than $1 \%$ of all transplacental haemorrhages) continued scoring of foetal cells in all cases might be thought to be justified, since they will require correspondingly high doses of anti-D (1,000 $\mu \mathrm{g}$. or more) to suppress Rh-immunization.

\section{Looking after Children}

The care of children for gain is regulated by the Nurseries and Child Minders Regulation Act, 1948, which empowers local health authorities to keep registers of premises where children are looked after and also of the persons looking after them. When children are received to be looked after for a day or a substantial part of it for reward, both the premises and the person must be registered.

Most local authorities exercise a strict control over registration and insist on a high standard to ensure that the person in charge of the children has reasonable qualifications and experience and that there is adequate supporting staff. In addition there must be suitable arrangements for feeding the children and provision for routine medical supervision. Arrangements must be made for a general practitioner to attend in cases of accidents or emergency, and all accidents must be notified to the local health authority. Play groups, as such, have no statutory position. A play group is either a full-time or a part-time day nursery according to the number of hours that it is open, and must be registered as such.

The Act is comprehensive, and any person caring for children for gain and not being registered would fall into the category of illegal day minder and would be the subject of prosecution. The only part of the Act which is ambiguous is that which refers to "a substantial part of the day," and this has never been clearly defined, but most local authorities would take a half-day or a session of three hours as being a substantial part of the day.

An application for registration does not mean automatic approval, and many applicants are disappointed, but they have recourse to an appeal in the courts. In fact, most local authorities take great care to help applicants in putting their premises in order, and when an application is refused it is usually because it is quite impossible for the person to care for children adequately.

Gross neglect of children by illegal day minders is uncommon. Usually it arises not from unkindness but from lack of thought in failing to provide sufficient space and facilities for the children. In some of the larger conurbations with immigrant populations and large groups of married students there has been a growing tendency for young children to be left with neighbours, who charge a nominal fee for looking after them, and it is here that the greatest danger arises, because usually the houses are inadequate for the purpose and the children are either put to bed for the whole day or left to sit around doing nothing. In such conditions there is grave danger to health.

Faulty feeding leading to malnutrition, and neglect of common symptoms of illness by untrained persons, together 